\title{
Highly Integrated WBG Power Module for Next Generation Plug-In Vehicles
}

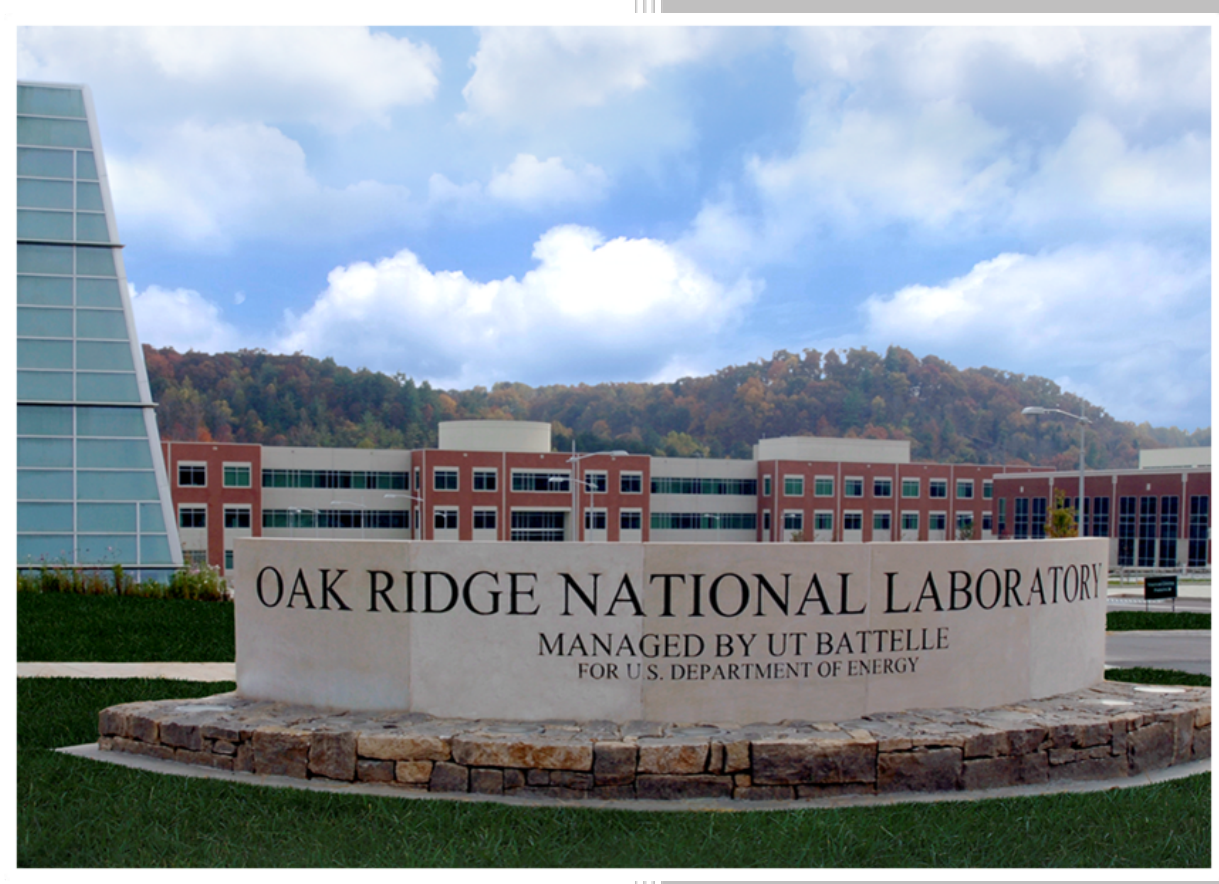

Approved for public release.

Distribution is unlimited.
A. A. Wereszczak
R. H. Wiles
B. A. Oistad
S. B. Waters
L. D. Marlino
B. Ozpineci
M. Jaksic
J. Czubay
B. Peaslee

February 2020 


\title{
DOCUMENT AVAILABILITY
}

Reports produced after January 1, 1996, are generally available free via US Department of Energy (DOE) SciTech Connect.

Website www.osti.gov

Reports produced before January 1, 1996, may be purchased by members of the public from the following source:

\author{
National Technical Information Service \\ 5285 Port Royal Road \\ Springfield, VA 22161 \\ Telephone 703-605-6000 (1-800-553-6847) \\ TDD 703-487-4639 \\ Fax 703-605-6900 \\ E-mail info@ntis.gov \\ Website http://classic.ntis.gov/
}

Reports are available to DOE employees, DOE contractors, Energy Technology Data Exchange representatives, and International Nuclear Information System representatives from the following source:

Office of Scientific and Technical Information

PO Box 62

Oak Ridge, TN 37831

Telephone 865-576-8401

Fax 865-576-5728

E-mail reports@osti.gov

Website http://www.osti.gov/contact.html

This report was prepared as an account of work sponsored by an agency of the United States Government. Neither the United States Government nor any agency thereof, nor any of their employees, makes any warranty, express or implied, or assumes any legal liability or responsibility for the accuracy, completeness, or usefulness of any information, apparatus, product, or process disclosed, or represents that its use would not infringe privately owned rights. Reference herein to any specific commercial product, process, or service by trade name, trademark, manufacturer, or otherwise, does not necessarily constitute or imply its endorsement, recommendation, or favoring by the United States Government or any agency thereof. The views and opinions of authors expressed herein do not necessarily state or reflect those of the United States Government or any agency thereof. 
ORNL/TM-2019/1395

CRADA/NFE-16-06206

Electrical and Electronics Systems Research Division

\section{Highly Integrated WBG Power Module for Next Generation Plug-In Vehicles}

A. A. Wereszczak, ${ }^{1}$ R. H. Wiles, ${ }^{2}$ B. A. Oistad,${ }^{2,3}$ S. B. Waters, ${ }^{1}$

L. D. Marlino, ${ }^{2}$ B. Ozpineci, ${ }^{2}$ M. Jaksic, ${ }^{4}$ J. Czubay, ${ }^{4}$ and B. Peaslee ${ }^{4}$

${ }^{1}$ Materials Science and Technology Division

Oak Ridge National Laboratory

Oak Ridge, TN 37831

${ }^{2}$ Electrical and Electronics Systems Research Division

National Transportation Research Center

Oak Ridge National Laboratory

Knoxville, TN 37932

${ }^{3}$ Oak Ridge Associated Universities

Oak Ridge, TN 37831

${ }^{4}$ General Motors - Electrification Electronics

Pontiac, MI 48340

February 2020

Prepared by

OAK RIDGE NATIONAL LABORATORY

Oak Ridge, TN 37831-6283

managed by

UT-BATTELLE, LLC

for the

US DEPARTMENT OF ENERGY

under contract DE-AC05-00OR22725 



\section{CONTENTS}

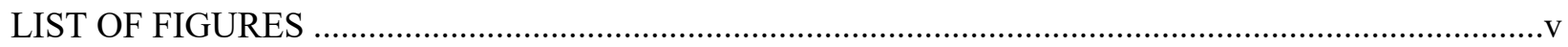

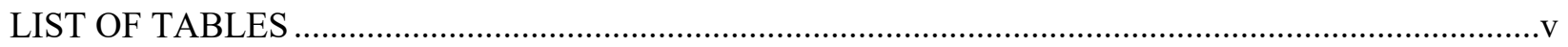

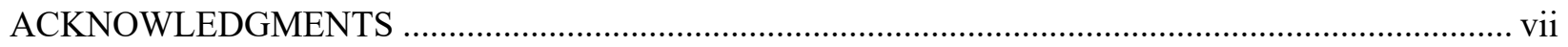

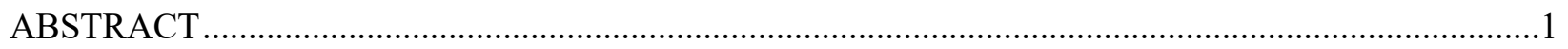

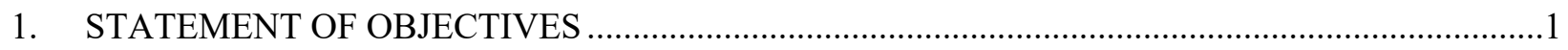

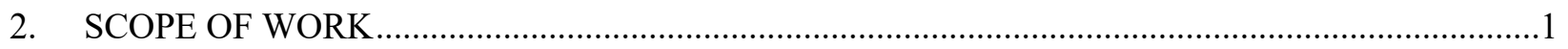

3. BENEFIT TO THE FUNDING DOE OFFICE'S MISSION ..................................................

4. TECHNICAL DISCUSSION OF WORK PERFORMED BY ALL PARTIES …...............................

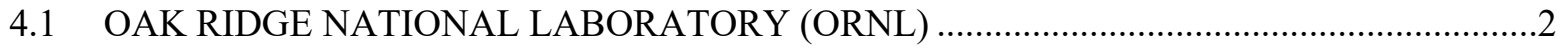

4.1.1 Task 1: Thermally-Cycled Ag-Sintered Interconnects ...............................................

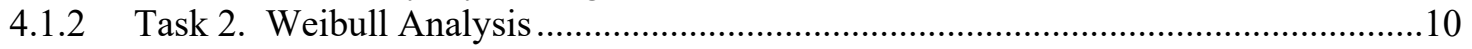

4.1.3 Task 3. Cross-Sectional Analysis of VA-Tech Interface ..........................................15

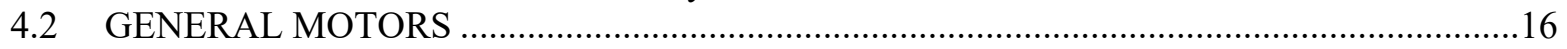

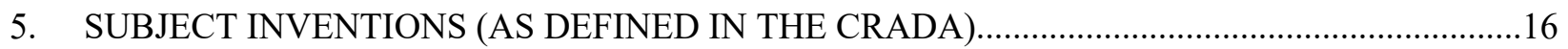

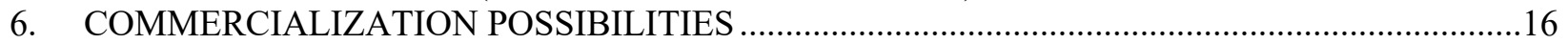

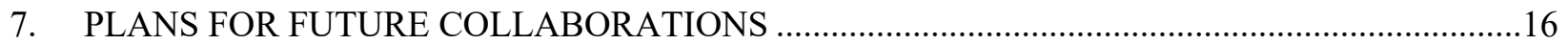

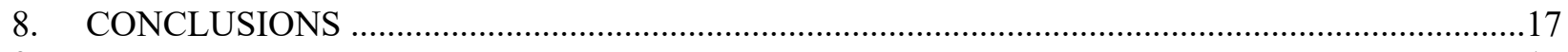

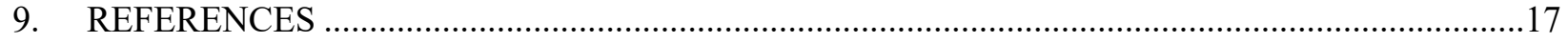





\section{LIST OF FIGURES}

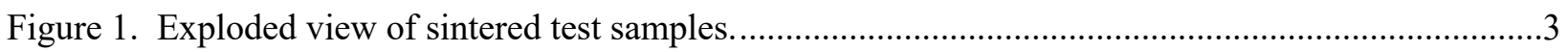

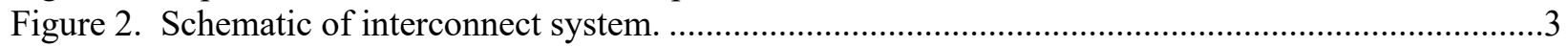

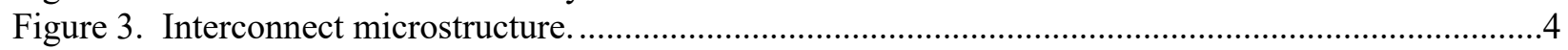

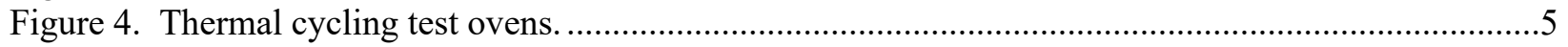

Figure 5. Interior of thermal cycling oven showing specimen support trays........................................5

Figure 6. Digital temperature sensors used to confirm uniform temperatures in the ovens. ......................6

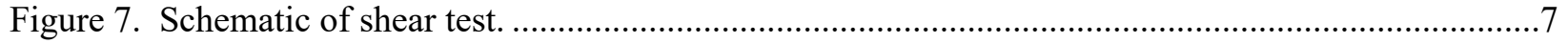

Figure 8. Shear stress as a function of number of thermal cycles............................................................

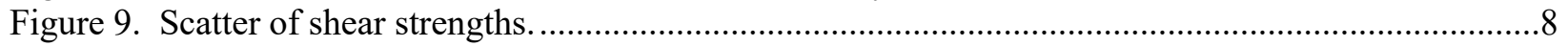

Figure 10. Top views of mating fracture surfaces. Porous sintered Ag structure on the left and

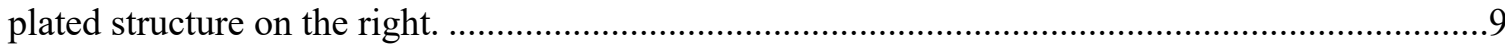

Figure 11. Side cross-section of fracture surface. The left image is a side view of the left image in Fig. 10. The arrows in the right image point to the interface or surface plane that is susceptible to shear-induced failure.

Figure 12. Comparison of 2- and 3-parameter Weibull distributions. ..................................................10

Figure 13. Comparison of Gaussian and 2-parameter Weibull distributions...........................................11

Figure 14. Comparison of unimodal, concurrent, and exclusive Weibull distributions. ...........................12

Figure 15. Schematics of concurrent and exclusive Weibull distributions............................................13

Figure 16. Examples of exclusive Weibull distributions found on the internet........................................13

Figure 17. Masking with a 3-parameter Weibull distribution................................................................14

Figure 18. Layout of VT-processed die with Ag-sintered interconnect. ..............................................15

Figure 19. Existing exudate about die (a) and shear-testing-tool hopping (b) illustrating inability

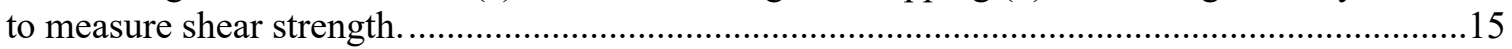

\section{LIST OF TABLES}

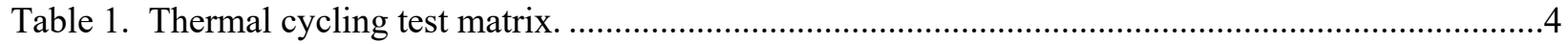

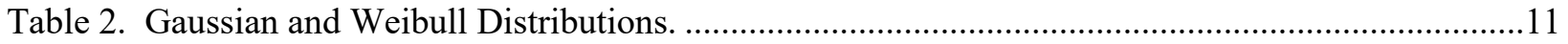





\section{ACKNOWLEDGMENTS}

ORNL's contribution to this research was sponsored by the U.S. Department of Energy, Assistant Secretary for Energy Efficiency and Renewable Energy, Vehicle Technologies Office, as part of the Batteries and Electrification Technologies Program, under contract DE-AC05-00OR22725 with UTBattelle, LLC.

The authors thank the US Department of Energy's S. Boyd for their financial support, and contributions from Oak Ridge National Laboratory's R. Parten (retired), S. Chowdhury, and E. Gurpinar, and General Motors's G. Smith (retired). 



\begin{abstract}
Current inverter technologies used in electric vehicles (EVs) are bulky, heavy, and expensive. The performance of the inverter is also limited by the traditional Si-based semiconductor and packaging technology. These constraints are responsible for extra weight and volume in the vehicle that reduces the driving range along with usable space within the vehicle. Moreover, operating temperature restrictions, and boundaries on the inverter location within the vehicle drastically reduces the inverter performance. Thus an improved inverter design is required for next generation electric vehicles.

The objective of this project was to research, develop and demonstrate a highly integrated WBG power module targeting the next generation of plugin hybrid electric vehicles (PHEVs). This power module needed to be functionally and mechanically optimized for General Motors (GM) traction inverter architecture. General Motors was the prime contractor, led the project, and oversaw the design, build, and test of the integrated power module. Virginia Polytechnic Institute and State University (VT) performed modeling and simulation tasks as well as power module design support. Monolith Semiconductor, Inc provided $\mathrm{SiC}$ dies and consulted on devices for the inverter. Oak Ridge National Laboratory (ORNL) performed power module technology evaluations, design evaluations of interconnect options, and performed material analysis and cross-sectioning of die activities.
\end{abstract}

\title{
1. STATEMENT OF OBJECTIVES
}

This project will result in a full-scale power module comprised of state of the art wide bandgap devices resulting in less expensive, smaller volume, lower maintenance, higher efficiency power electronics for automotive applications.

The research resulting from this project will be used in a voltage source inverter which is projected to achieve or exceed the DOEs 2020 targets (specific power, power density and cost targets of $14.1 \mathrm{~kW} / \mathrm{kg}$, $13.4 \mathrm{~kW} / 1$ and $\$ 3.3 / \mathrm{kW}$ ) while operating at higher efficiencies and current $\mathrm{Si}$ inverters.

\section{SCOPE OF WORK}

The work at ORNL had three tasks. The first was to thermally cycle pressureless Ag-sintered interconnects processed at ORNL and interpret if that cycling affected residual interconnect strength. The second was to introduce enhanced Weibull analysis and interpretation capabilities to GM-collaborators. The third was to provide postmortem characterization of GM-supplied devices that were fabricated at VT.

\section{BENEFIT TO THE FUNDING DOE OFFICE'S MISSION}

This work was part of the EERE Vehicle Technologies Office and was specifically referenced as an R\&D agreement in the Power Electronics and Electric Motors Program. The subject agreement will leverage DOE funds via the in-kind contributions of General Motors and will provide a path for the commercialization of technologies developed. 


\section{TECHNICAL DISCUSSION OF WORK PERFORMED BY ALL PARTIES}

\subsection{OAK RIDGE NATIONAL LABORATORY (ORNL)}

\subsubsection{Task 1: Thermally-Cycled Ag-Sintered Interconnects}

The primary objective of this task was to examine if the shear strength of ORNL-reflow-ovenprocessed test coupons, that were fabricated using pressureless Ag-sintered interconnects, would change when they were thermally cycled. The interconnects for this study were processed using a commercially available Ag paste with contact-drying and pressureless Ag-sintering using a continuous belt-style reflow oven utilizing a method developed at ORNL [1-2].

Over one hundred samples ("DBC sandwiches" like those used in Refs. 1-2 and schematically shown in Fig. 1) were fabricated and subjected to thermal cycling between $140^{\circ} \mathrm{C}$ and $-40^{\circ} \mathrm{C}$. Each DBC sandwich consisted of two electrolytically-Ag-plated, direct bonded copper aluminum oxide ceramic substrates bonded together by a pressureless Ag-sintered interconnect. The description of the combination of the plating method and these substrates are described elsewhere [3]. The sinterable Ag paste for the interconnect is commercially available (Henkel, Loctite Ablestik SSP 2020). Its processing methods, adapted to sintering using a continuous, belt-style reflow oven, are described in detail in Refs. 1-2. The substrates were $12.7 \times 12.7 \mathrm{~mm}$ and the interconnect is circular, centrally printed on the substrate, and had a diameter of $5 \mathrm{~mm}$. A schematic of the interconnect's structure is shown in Fig. 2 and a scanning electron microscopy image of a polished cross-section of it is shown in Fig. 3.

The employed thermal cycling test matrix is shown in Table 1 and images of the test equipment used for that are shown in Figs. 4-6. The "Standard" thermal cycle took 82 minutes per cycle, and consisted of a $5^{\circ} \mathrm{C} / \mathrm{min}$ heating rate to $140^{\circ} \mathrm{C}$, a 5 minute soak, a $5^{\circ} \mathrm{C} / \mathrm{min}$ cooling rate down to $-40^{\circ} \mathrm{C}$, a 5 minute soak, and then return to $20^{\circ} \mathrm{C}$ at $5^{\circ} \mathrm{C} / \mathrm{min}$. The "Faster" thermal cycle employed $10^{\circ} \mathrm{C} / \mathrm{min}$ heating and cooling rates and took 46 minutes/cycle. The objective of using the latter was to see if an accelerated heating cycle would affect the measured response of retained shear strength. Temperature sensors were positioned throughout the oven to confirm temperature uniformity, and their responses (Fig. 6) indicated sufficient uniformity produced by the ovens.

* Certain commercial materials or equipment are identified to adequately describe the experimental procedure. This does not imply their endorsement by the Oak Ridge National Laboratory, UT-Battelle, the US Department of Energy, and General Motors, nor that these materials and equipment are necessarily the best choices for these purposes. 


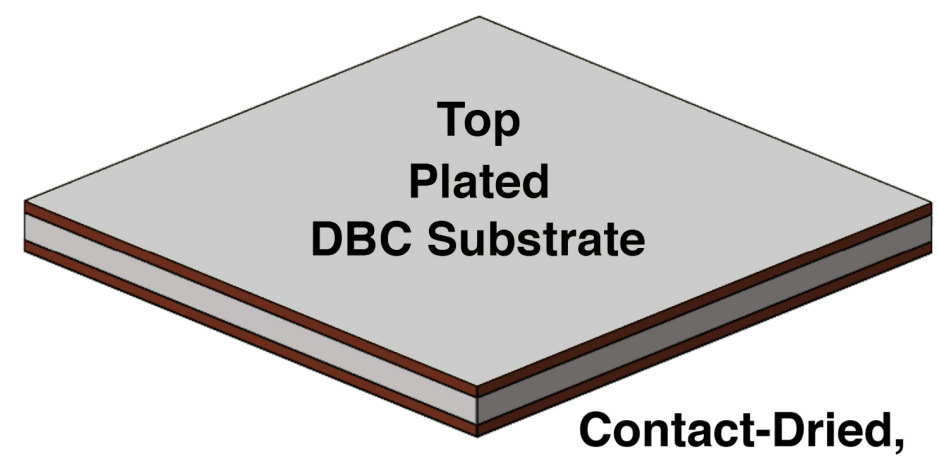

5-mm-Diameter, Printed Ag Pad

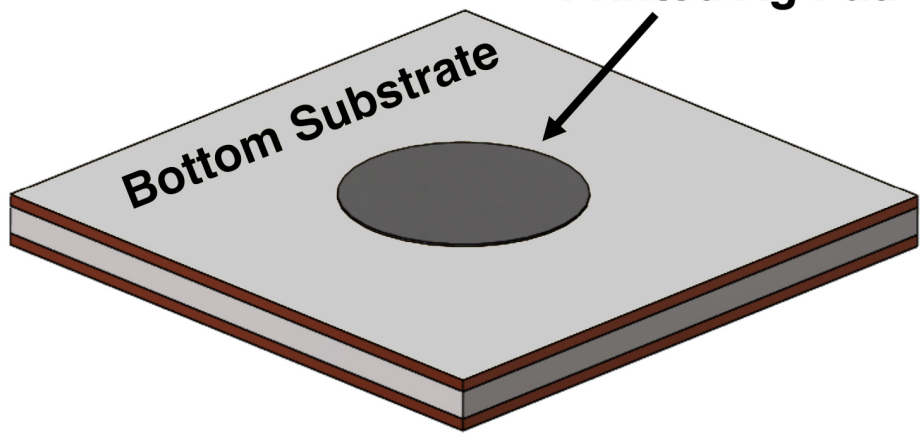

Figure 1. Exploded view of sintered test samples.

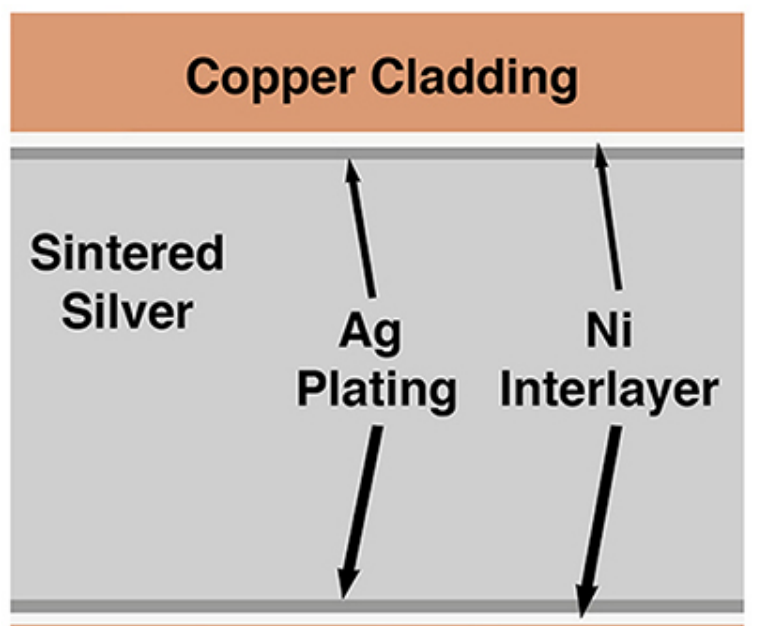

Copper Cladding

Figure 2. Schematic of interconnect system. 

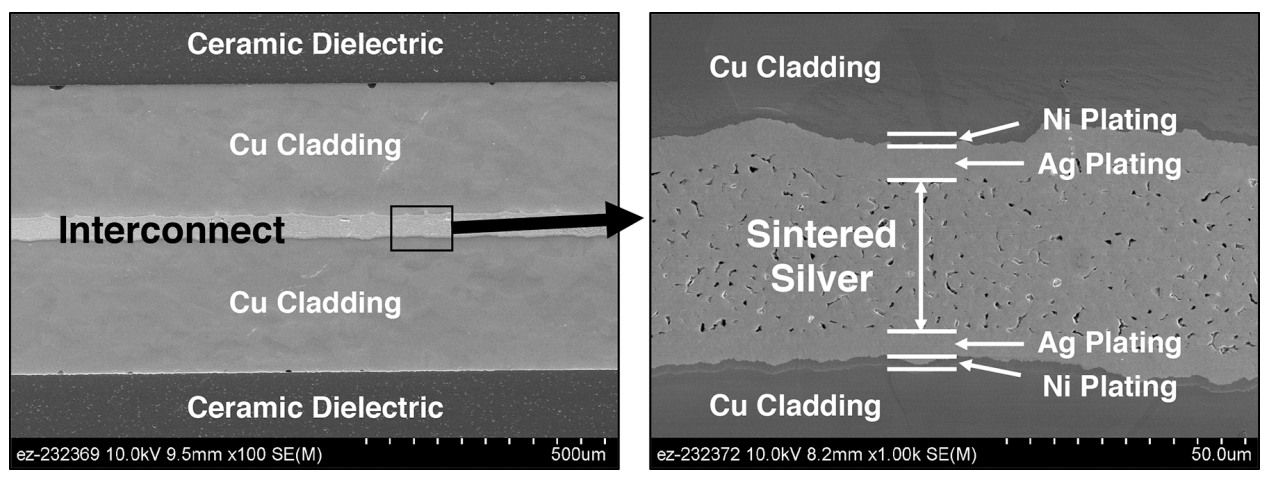

Figure 3. Interconnect microstructure.

Table 1. Thermal cycling test matrix.

\begin{tabular}{|c|c|c|}
\hline $\begin{array}{c}\text { \# of } \\
\text { Cycles }\end{array}$ & $\begin{array}{c}\text { Standard } \\
\text { Cycle }\end{array}$ & $\begin{array}{c}\text { Faster } \\
\text { Cycle }\end{array}$ \\
\hline 0 & \multicolumn{2}{|c|}{$\mathrm{X}=10$ samples } \\
\hline 100 & $\mathrm{X}$ & $\mathrm{X}$ \\
\hline 200 & $\mathrm{X}$ & $\mathrm{X}$ \\
\hline 300 & $\mathrm{X}$ & $\mathrm{X}$ \\
\hline 400 & $\mathrm{X}$ & \\
\hline 500 & $\mathrm{X}$ & \\
\hline 600 & $\mathrm{X}$ & \\
\hline 700 & $\mathrm{X}$ & \\
\hline 800 & $\mathrm{X}$ & \\
\hline 900 & $\mathrm{X}$ & \\
\hline 1000 & $\mathrm{X}$ & \\
\hline
\end{tabular}




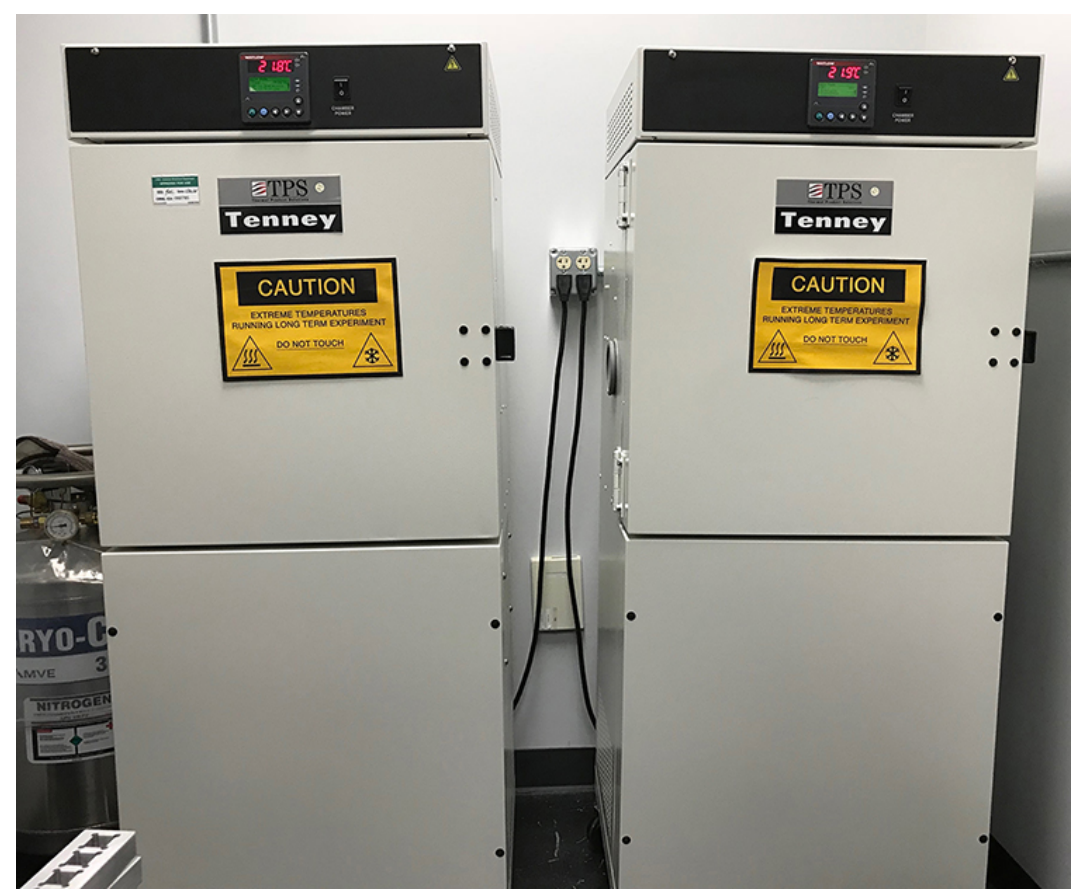

Figure 4. Thermal cycling test ovens.

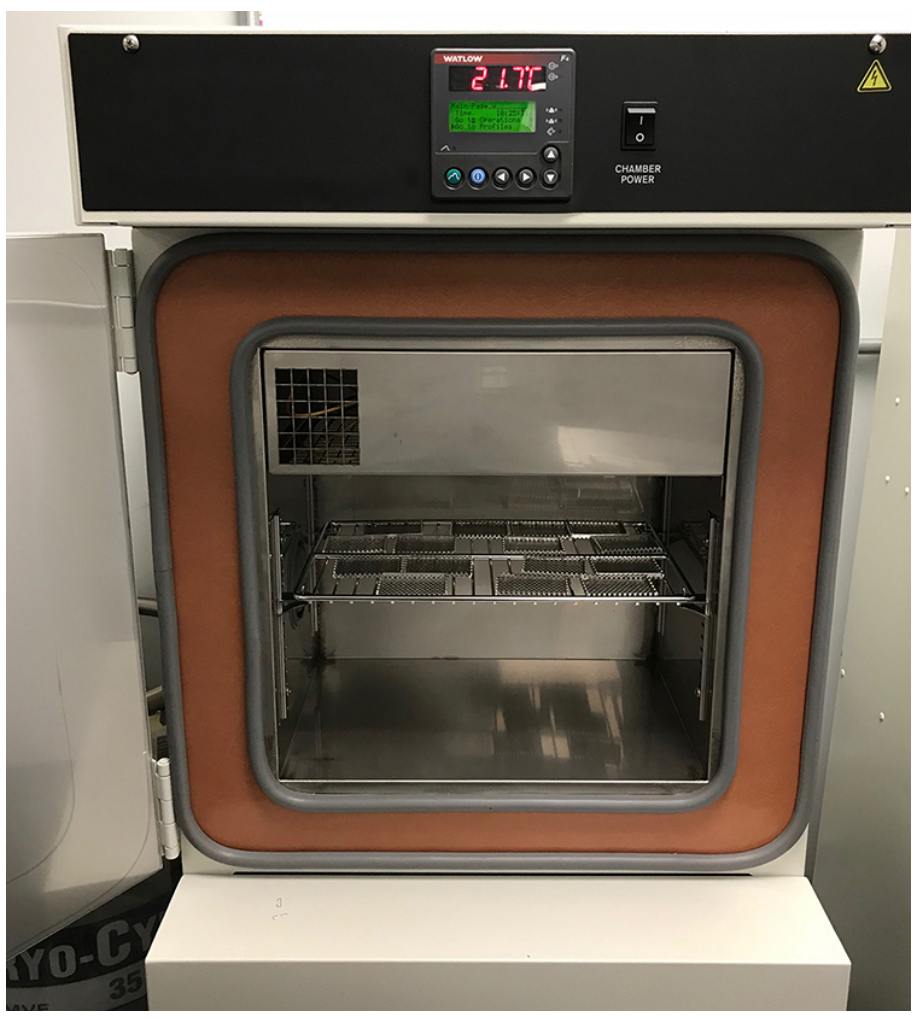

Figure 5. Interior of thermal cycling oven showing specimen support trays. 


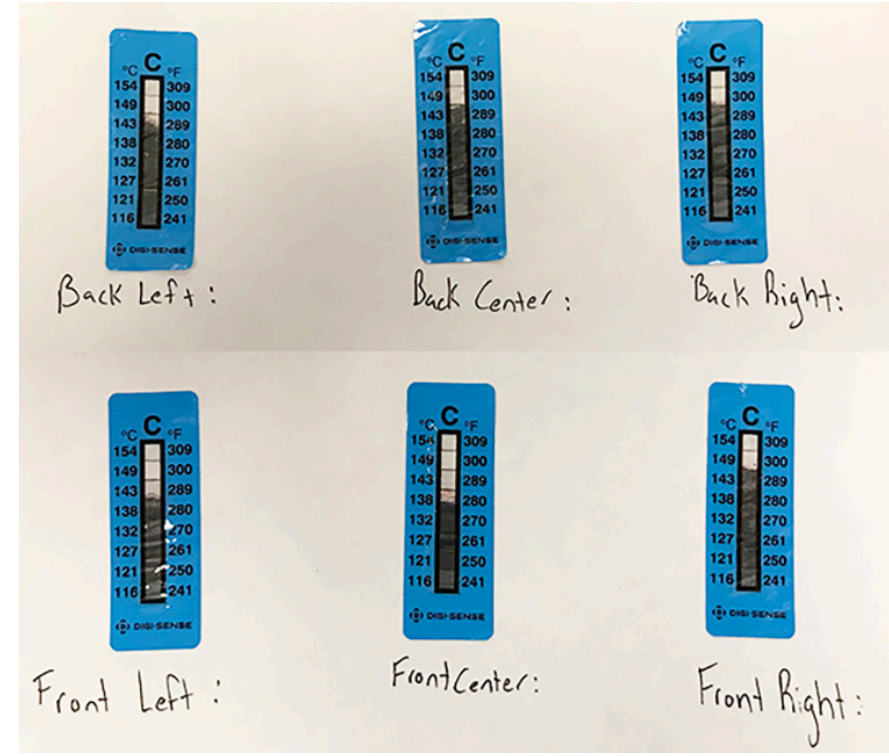

Figure 6. Digital temperature sensors used to confirm uniform temperatures in the ovens.

Destructive mechanical testing of the DBC substrate sandwiches was performed using a commercial shear tester (4000 Bondtester, Nordson Dage, Fremont, CA) to determine the maximum shear stress at failure of all specimens. Load cell calibration was confirmed pre- and post-testing. All testing was done at room temperature. The substrate that had been printed on was gripped using a stationary vice fixture while a shear testing tool horizontally contacted the mated substrate. A schematic of this is shown in Fig. 7. The bottom of the shear testing tool was positioned at a height aligned with the bottom of the aluminum oxide substrate within the top DBC substrate. The tool had a 15-mm-width and passively rotated and aligned itself against the specimen under a light compressive force. For the testing, horizontal loading is applied using a constant displacement rate of $25 \mu \mathrm{m} / \mathrm{s}$ until fracture occurred. The force at failure was recorded for each specimen.

Each specimen's maximum shear stress at failure, $\tau_{\max }$, was then calculated using the combination of the moment of inertia of a circle (i.e., the printed sintered-Ag pad shape) and the expression for maximum shear stress [4] or:

$$
\tau_{\max }=\frac{P_{\max }(3+2 v)}{2 \pi(1+v) r^{2}}
$$


where $P_{\max }$ is the recorded failure force for each specimen, $v$ is the Poisson's ratio of the sintered-Ag (taken as 0.15 here for $50 \%$ porous sintered silver [5]), and $r$ is the circular print-pad's radius. The nominal print radius was $2.5 \mathrm{~mm}$; however, its dimension was post-test measured for each specimen and that value was used to calculate $\tau_{\max }$. The maximum stress calculated using Eq. 1 is $7.6 \%$ larger than the average stress calculated using the classical beam equation for shear and a circular shape (i.e., $\tau=4 P_{\max } / 3 \pi r^{2}$ ). Equation 1 and its calculation of $\tau_{\max }$ is preferentially used in this study because the Poisson's effect is not considered in the classical beam equation and failure initiation occurs from a maximum applied stress and not an average applied stress [6]. Therefore, if this Poisson's effect is not considered, then the classical beam equation for average shear stress at failure is inaccurate and too low by $7.6 \%$. The maximum shear failure stresses calculated from Eq. 1 for each of the test sets were fitted with a two-parameter Weibull distribution using maximum likelihood estimation as well as a Gaussian distribution using commercially available software (WeibPar, Connecticut Reserve Technologies, Gates Mills, OH).

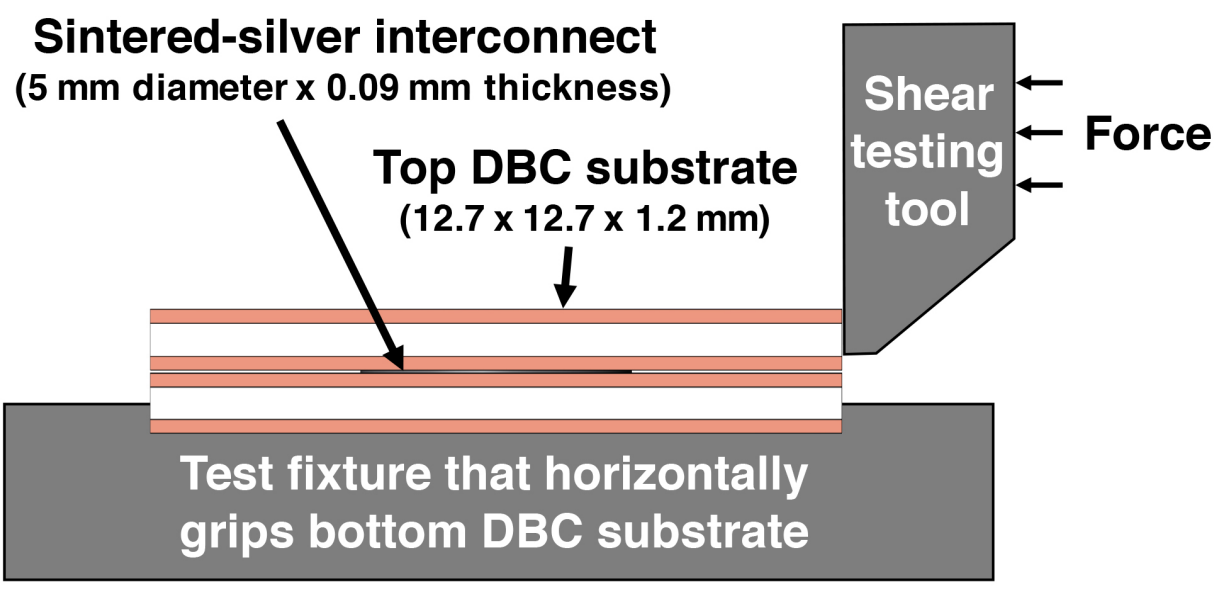

Figure 7. Schematic of shear test.

The average shear failure stresses as a function of the number of thermal cycles are shown in Fig. 8 . Average shear strength decreased slightly between 0 and 100 cycles but was $\sim 50 \mathrm{MPa}$ and remained statistically equivalent through 1000 cycles. Nearly all the specimens had a shear failures stress greater than $40 \mathrm{MPa}$ as shown in the strength-scatter-plot of Fig. 9. Additionally, the failure stress is statistically equivalent for the two test cycles which could be an important finding for future testing as the entire duration of testing may be decreased. 


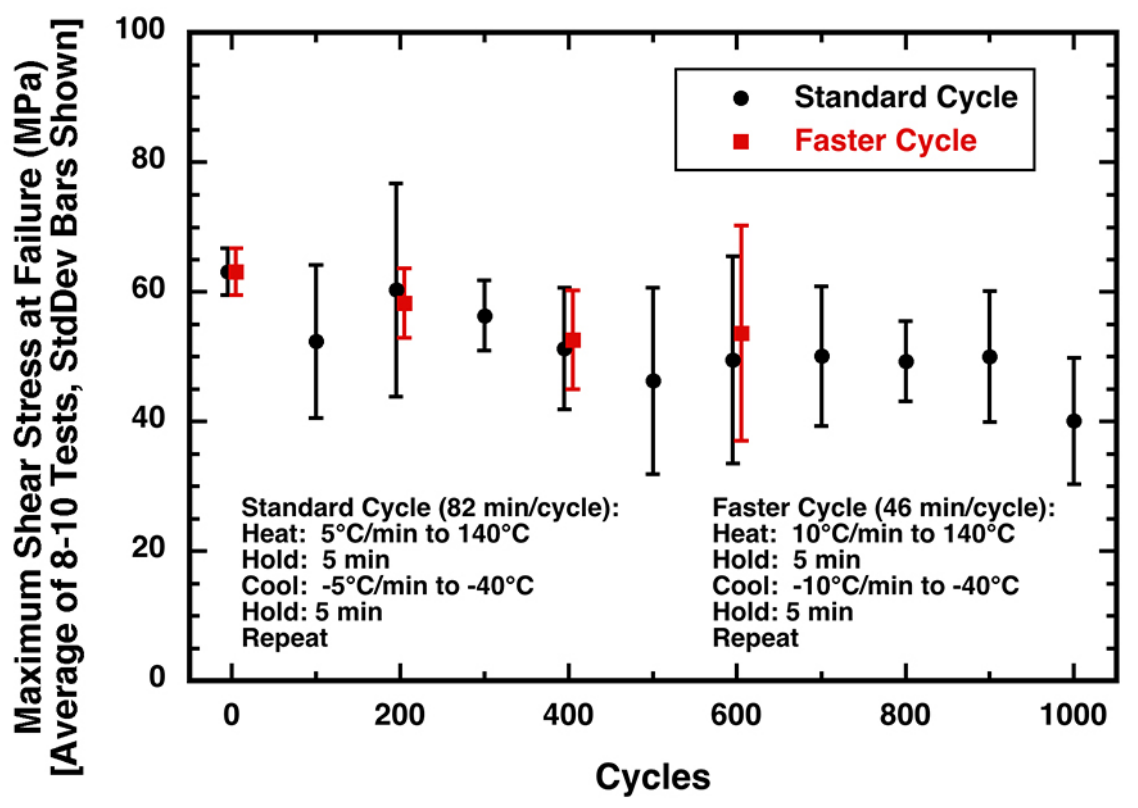

Figure 8. Shear stress as a function of number of thermal cycles.

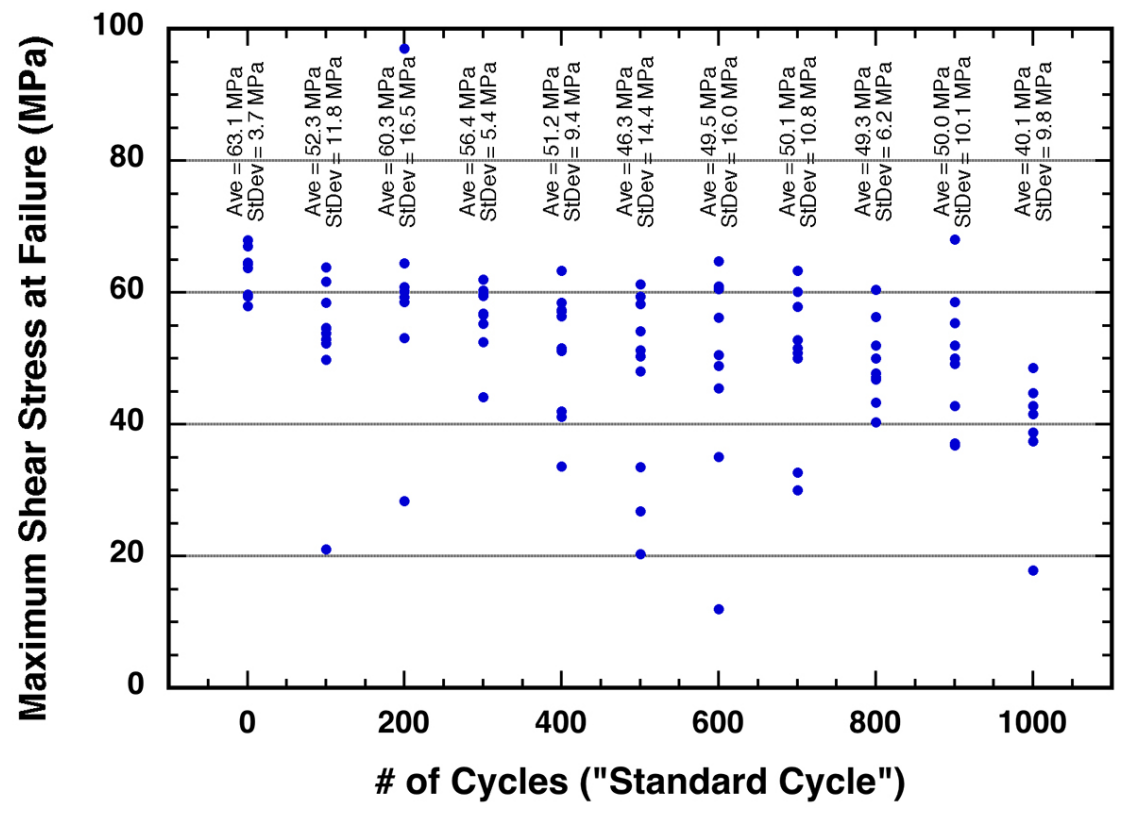

Figure 9. Scatter of shear strengths. 
Failure due to shear testing tended to occur at one of the two interfaces between the sintered silver interconnect and the Ag-plating, and an illustration of that are shown in Figs. 10-11. For failure to occur there, the cohesive strength of the sintered silver must be larger than the adhesive strength of that interface; that is an indicator that the cohesive strength of the sintered silver is relatively high. But that interface is a location where a porous (lower stiffness) Ag structure and solid (higher stiffness) Ag structure are bonded; when that interface is sheared, a stress concentration inherently exists because of that dissimilarity in stiffness. Therefore, failure may be preordained to occur there (where arrows are pointing in the right image in Fig. 11) when the porous sintered-silver interconnect and the plating material both are of good quality and both have good cohesive strength.

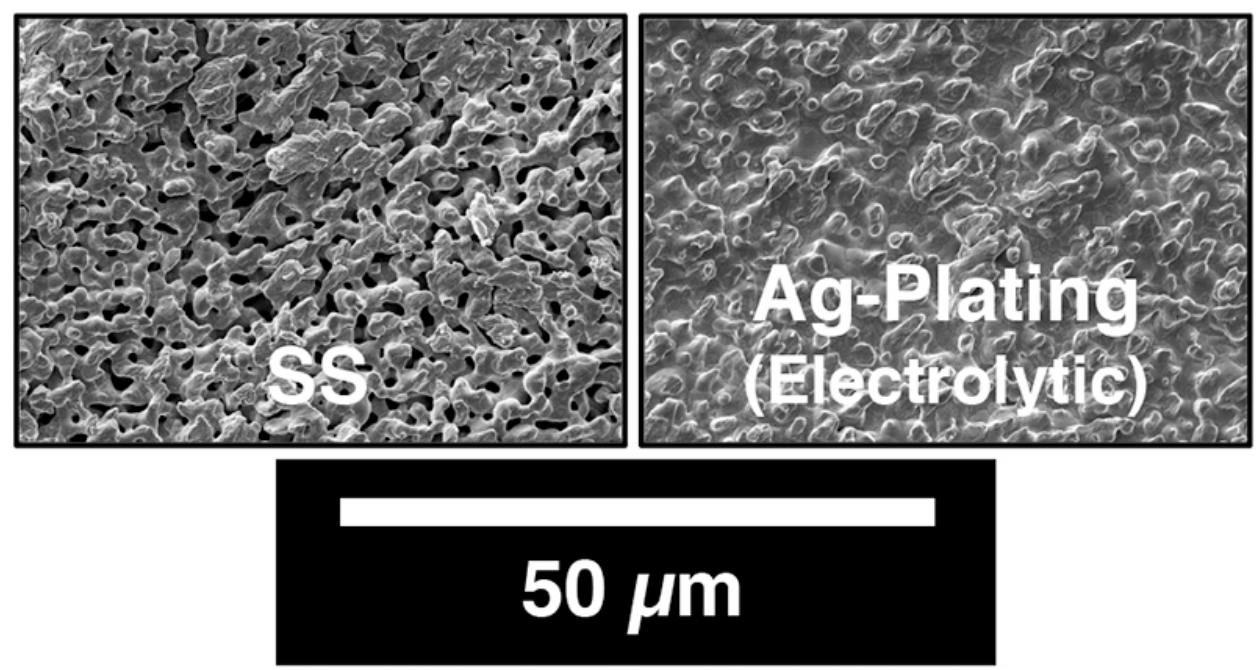

Figure 10. Top views of mating fracture surfaces. Porous sintered Ag structure on the left and plated structure on the right.
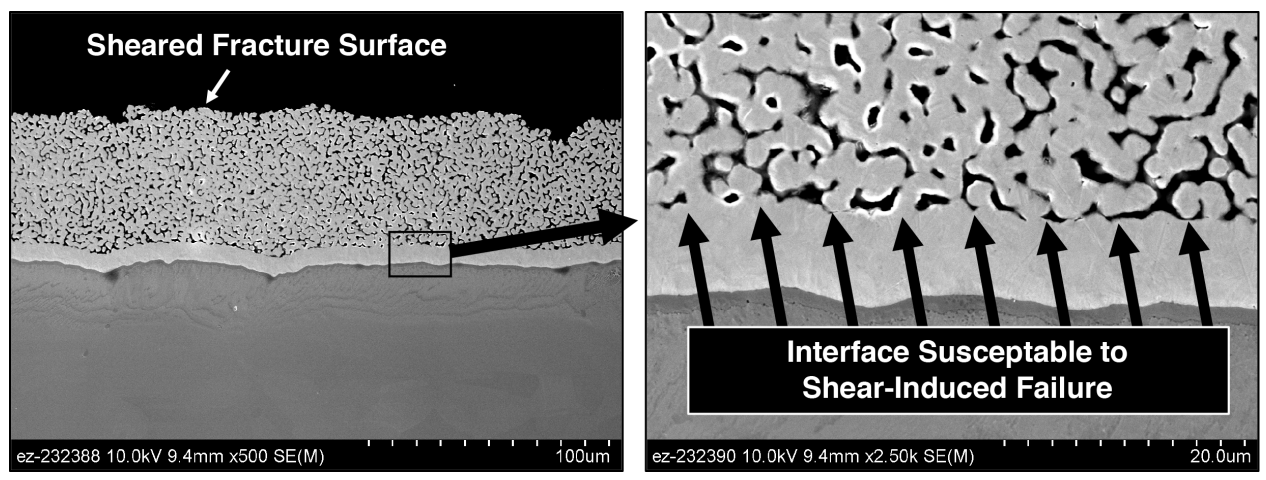

Figure 11. Side cross-section of fracture surface. The left image is a side view of the left image in Fig. 10. The arrows in the right image point to the interface or surface plane that is susceptible to shear-induced failure. 


\subsubsection{Task 2. Weibull Analysis}

The objective of this sub-effort was to potentially assist GM in their analysis of component failure statistics when using a Weibull distribution [7] for representation. ORNL has a long history of employing Weibull distribution analysis beyond just the statistical analysis, using it to help make judgments about the consistency of a process or the testing of a dependent parameter or both. ORNL assisted GM with such analysis and interpretations with the outcome being enhanced commercial software (WeibPar) being delivered to GM.

The utilization and interpretation of the two-parameter Weibull distribution were primarily focused on in this sub-task. The two- and three-parameter Weibull distributions are illustrated in Fig. 12, with the former contrasted in Fig. 13 and Table 2 with the familiar Gaussian or normal distribution. For a given response of a material or system (e.g., strength, cycles to failure, time to failure, etc.), a good performer will have a large characteristic value (Weibull) or high average value (Gaussian). When that response shows low scatter, then the shape parameter or modulus (Weibull) will be high-valued and its standard deviation (Gaussian) will be low-valued.

\section{Two-Parameter $\left(\mathrm{m}, \sigma_{\theta}\right)$}

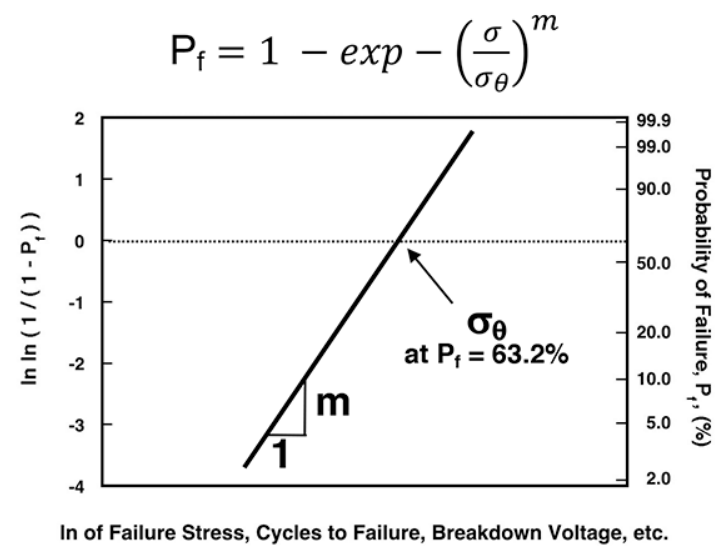

\section{Three-Parameter $\left(\mathrm{m}, \sigma_{\mathrm{u}}, \sigma_{\theta}\right)$}

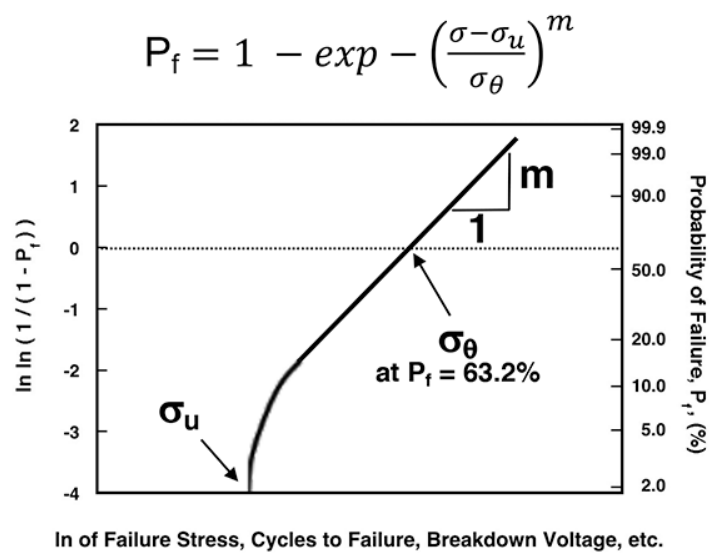

Figure 12. Comparison of 2- and 3-parameter Weibull distributions. 


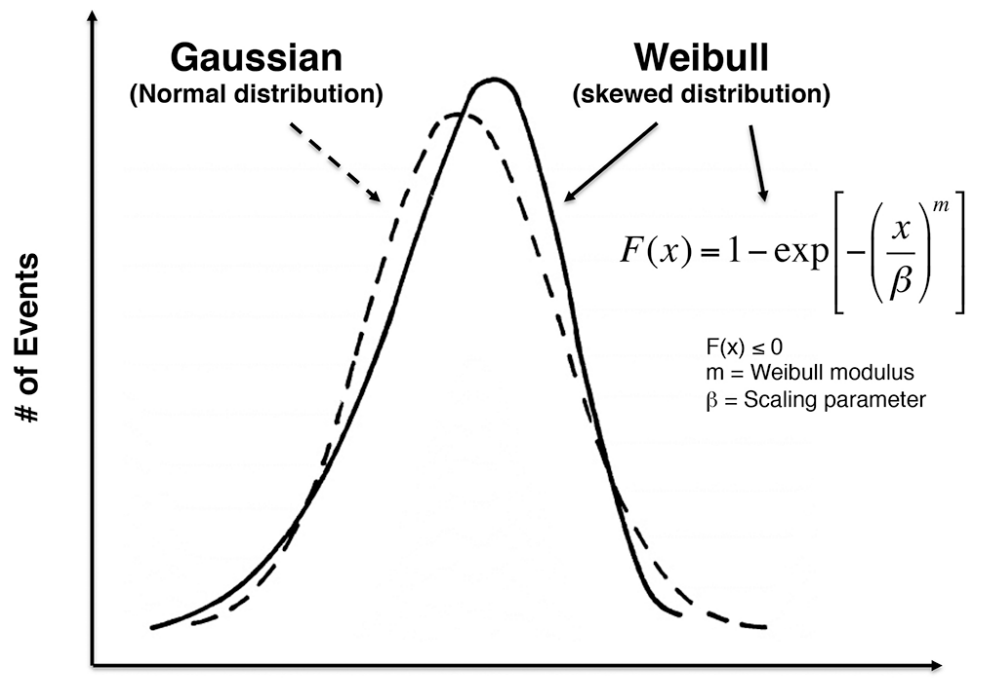

Strength, Cycles to Failure, Breakdown Voltage, etc.

Figure 13. Comparison of Gaussian and 2-parameter Weibull distributions.

Table 2. Gaussian and Weibull Distributions.

\begin{tabular}{|c|c|c|}
\hline Distribution & Descriptor & Scatter \\
\hline $\begin{array}{l}\text { Gaussian or } \\
\text { Normal }\end{array}$ & Average & Standard deviation \\
\hline $\begin{array}{c}\text { Weibull } \\
\text { (2-parameter) }\end{array}$ & $\begin{array}{l}\text { Scaling parameter or characteristic } \\
\text { - strength, } \\
\text { - breakdown voltage, } \\
\text { - time to failure, } \\
\text { - cycles to failure, } \\
\text { - etc. }\end{array}$ & $\begin{array}{l}\text { Shape parameter or } \\
\text { Weibull modulus }\end{array}$ \\
\hline
\end{tabular}


More involved interpretations result when there are two or more operative distributions in a set of test data (there is almost always 2 or more operative distributions in a data set each having different slopes). An example of such is shown in Fig. 14, where two operative sets are either portrayed as concurrent or exclusive, and which have "knees" in their curves directed one way or the other. Concurrent and exclusive sets can be represented by the simple chain-analogy schematic shown in Fig. 15. For two concurrent distributions, the performance limiting flaw in both distributions exists in all specimens (or testing) whereas they do not in two exclusive sets. This will manifest itself in curves like that shown in Fig. 14.

That observed response of concurrency or exclusivity is important to an engineer or designer or tester because it can be an indicator of an immature process or that testing is not being consistently done or both [8]. A response that exhibits two or more existing concurrent population sets suggests the part or assembly or system was consistently fabricated and tested. However, a response that exhibits two or more exclusivity data sets is an indication that the same performance limiter does not exist in every part or assembly or system (e.g., poor batch of solder was inadvertently introduced, etc.), or they were not consistently tested (e.g., instrumentation calibration failed during the testing and that was undetected) or both. Therefore, when exclusive-like data sets are evident in a Weibull plot, they should be viewed as an indicator that something may not be right with the process or testing. There is much evidence of the existing exclusivity in many data sets, see Fig. 16; their responses should elicit caution and cause further exploratory forensics to the engineer, designer, or tester.

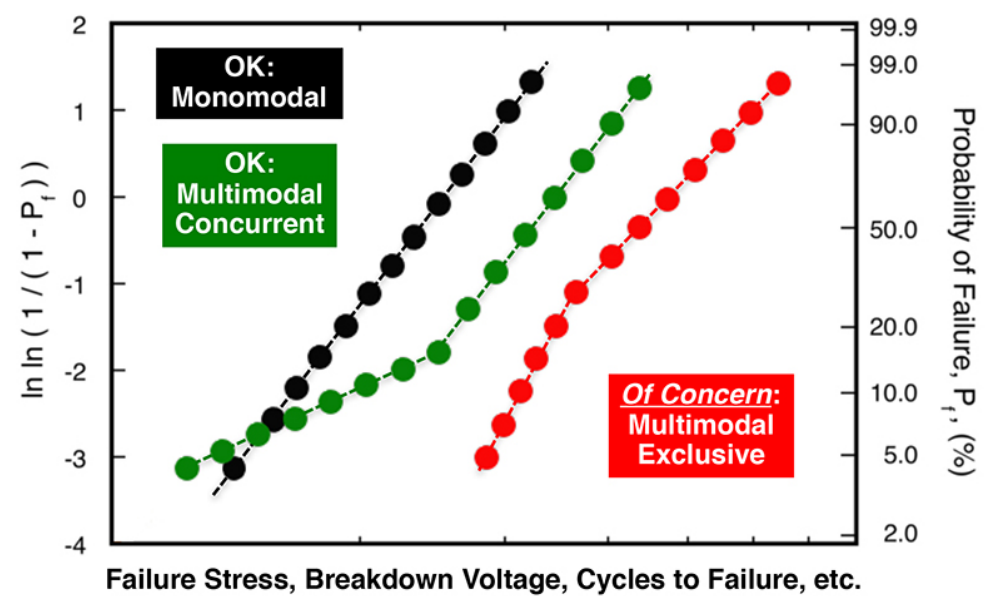

Figure 14. Comparison of unimodal, concurrent, and exclusive Weibull distributions. 

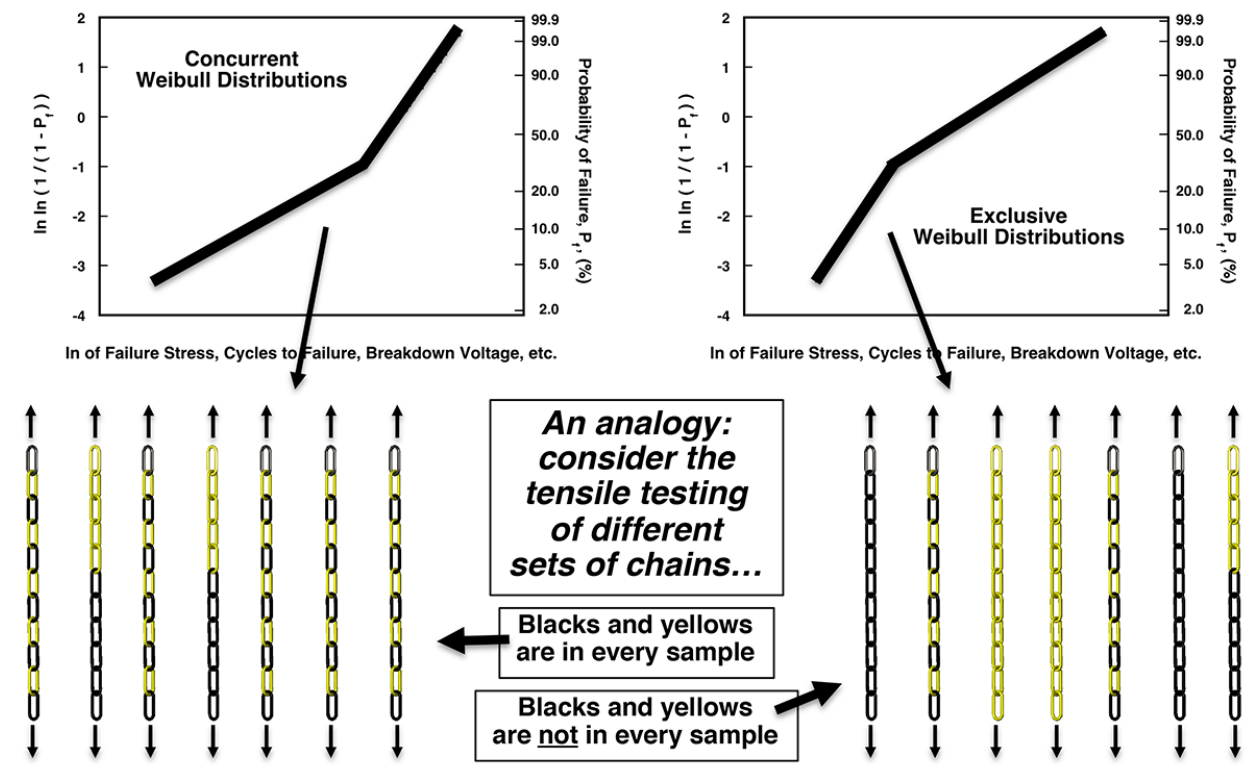

Figure 15. Schematics of concurrent and exclusive Weibull distributions.
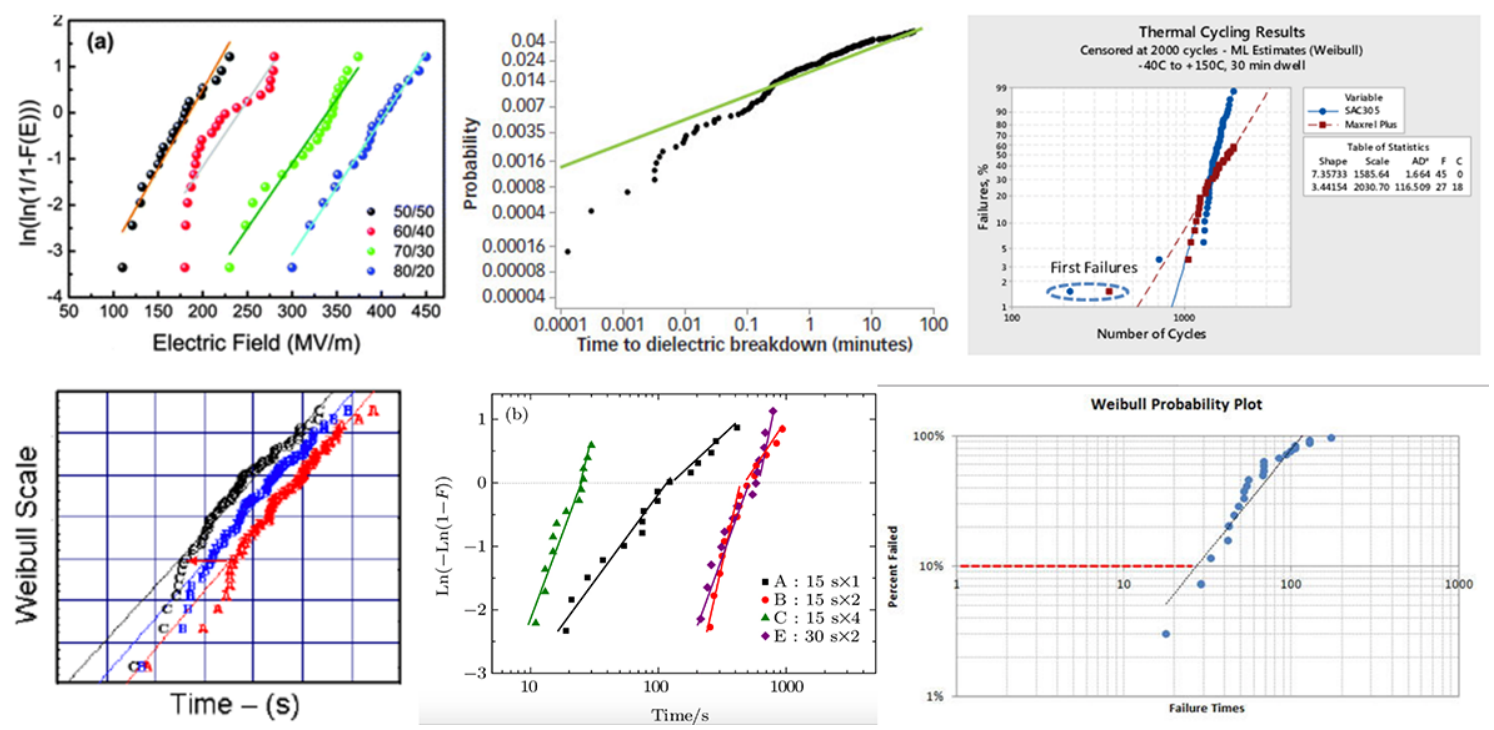

Figure 16. Examples of exclusive Weibull distributions found on the internet. 
A potentially grave mistake that many engineers or designers or testers make is, rather than interpret what is causing exclusivity, they attempt to statistically fit it with a 3-parameter Weibull distribution and attempt to manage production or testing with it. This is illustrated in Fig. 17. This may make the statistical portrayal of a data set "cleaner" as illustrated in the right-hand graph in Fig. 17; however, it is potentially masking an inherent problem with the fabrication process or the testing or both.

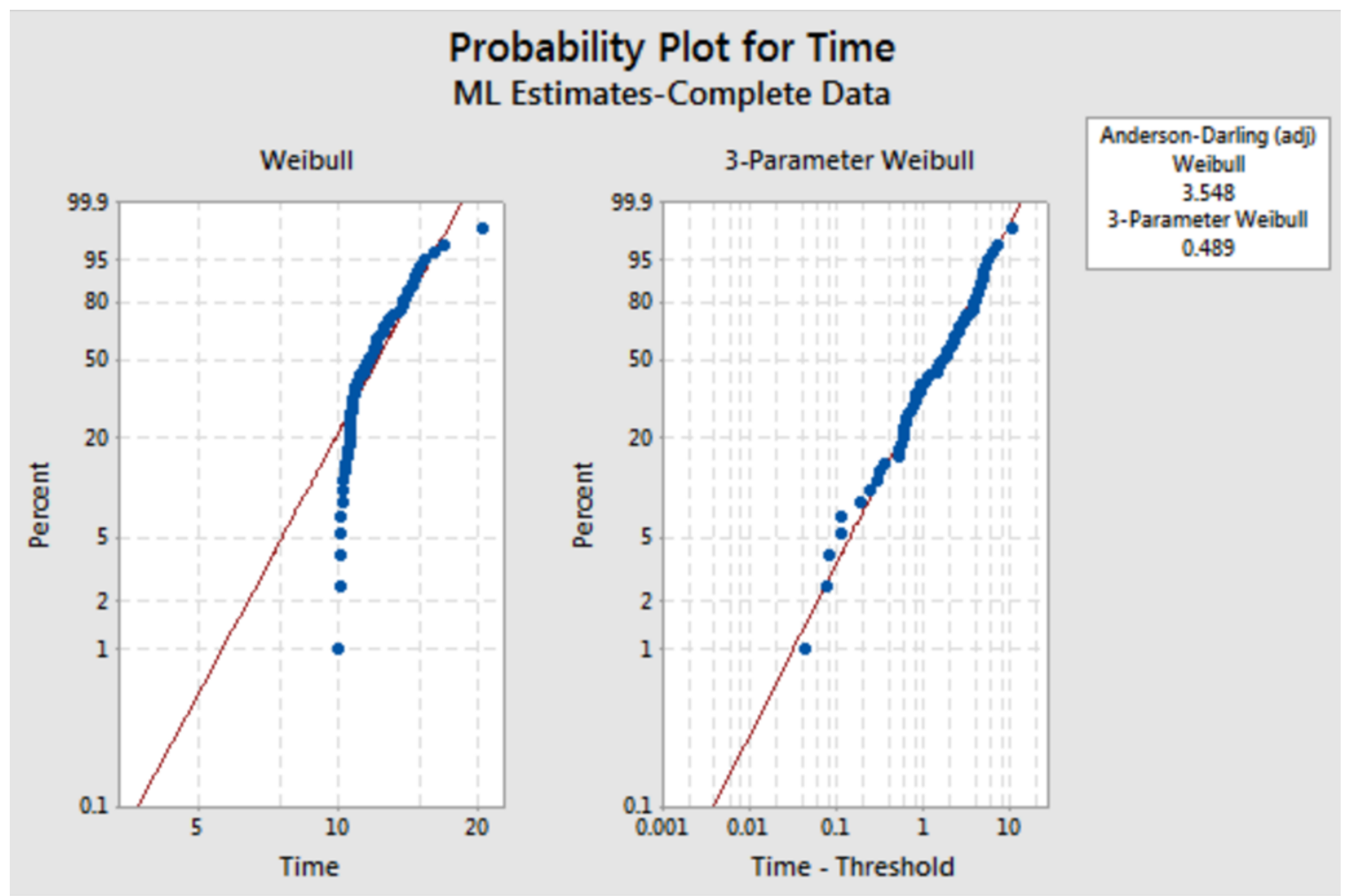

Figure 17. Masking with a 3-parameter Weibull distribution.

The above issues were illustrated to GM as part of ORNL's support, and as a consequence of that, interest existed to improve capabilities of a commercial Weibull distribution software (WeibPar - used by ORNL and many other institutions and research laboratories) that would better cater to the needs of confidence band estimation of Weibull distributions. In particular, there was a desire to determine userdefined confidence estimates down to low probability of failures (or its converse - high probability of survival). The previous capability of WeibPar could not generate user-chosen confidence bounds down to $0.001 \%$. The software vendor (Connecticut Reserve Technologies) was issued a subcontract via ORNL to enhance the software to be able to generate such confidence bounds down to a $0.001 \%$ probability of failure. The enhanced software was completed, and General Motors was supplied a perpetual license of the enhanced WeibPar. 


\subsubsection{Task 3. Cross-Sectional Analysis of VA-Tech Interface}

A Virginia Tech processed device was provided to ORNL in 2017 for shear testing; however, that testing could not be accommodated because its sintered-Ag interconnect exuded out from under the die and wetted up on the die's four sides precluding it from being shear tested. The resulting meniscus inhibited the ability to mechanically load in a secure manner against the die causing the tool to scrape over the side. Scanning electron microscopy (SEM) and energy dispersive spectroscopy (EDS) showed that a $\mathrm{Cu}-\mathrm{Pb}-\mathrm{Sn}$ solder had been used to bond the DBC substrate to the electrodes, and sintered silver was the interconnect between the semiconductor chip and the DBC substrate. Those issues are illustrated in Figs. 18-19.

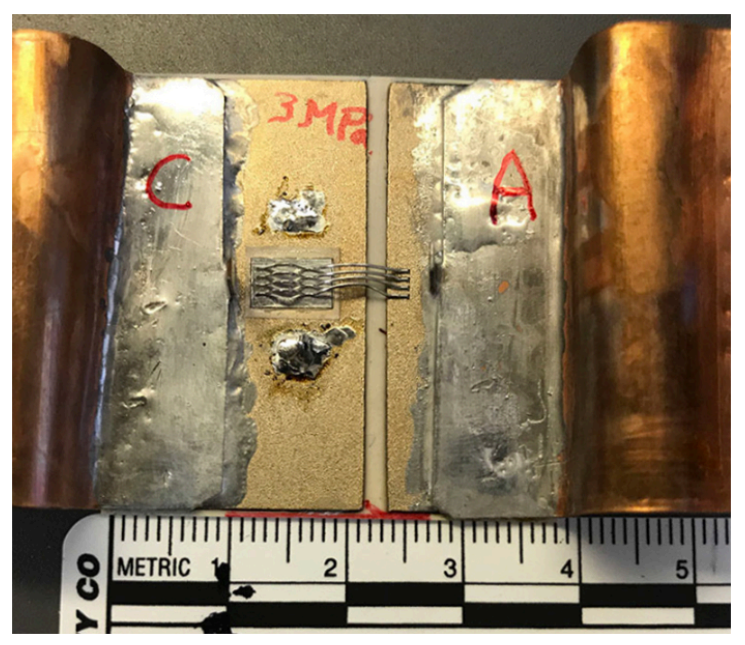

Figure 18. Layout of VT-processed die with Ag-sintered interconnect.
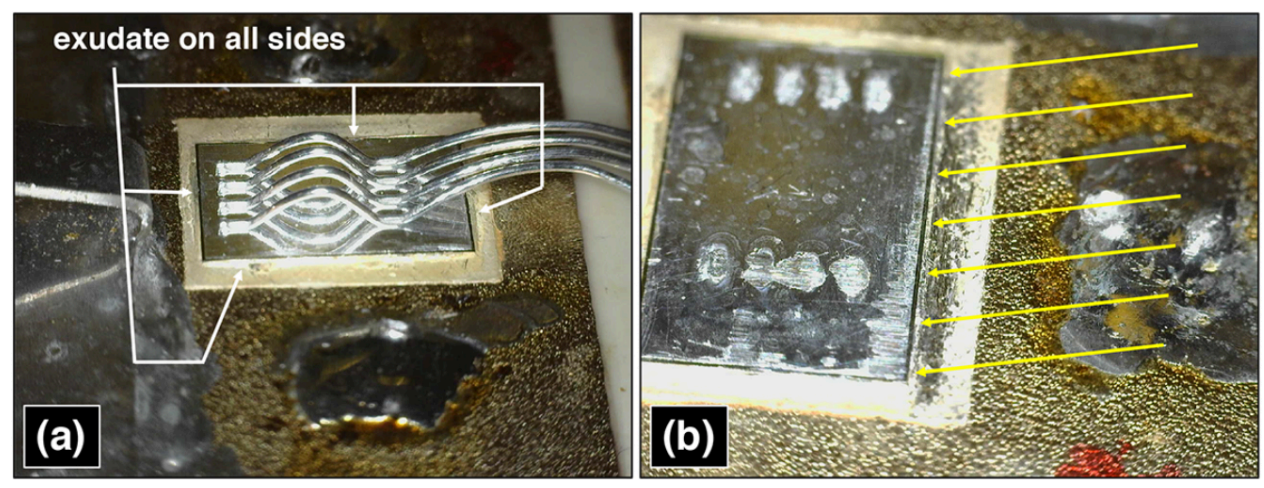

Figure 19. Existing exudate about die (a) and shear-testing-tool hopping (b) illustrating inability to measure shear strength. 


\subsection{GENERAL MOTORS}

The main work done was to prototype the new power module that would have improved capability. The proposed power module uses 4 die in parallel, reducing the overall cost while still operating with low conversion losses. The main improvements of the power module are to use the sintering process to attach die to the substrate, which was supported by ORNL through the preliminary study of thermally-aged Ag sintered interconnect.

The enhanced Weibull analysis will be used to estimate the lifetime of the power module in the next phase. Once power cycling tests are completed, the goal is to use Weibull analysis to estimate the lifetime capability of the power module. Virginia Polytechnic Institute and State University developed a sintered power module that can be used for traction inverter application with similar properties to GM power module design. Oak Ridge National Laboratory conducted some cross-sectional analysis of VT power module to provide more technical insight into the feasibility and quality of pressure-less sintering.

\section{SUBJECT INVENTIONS (AS DEFINED IN THE CRADA)}

There were no inventions conceived or first reduced to practice as a consequence of the completion of this project's work.

\section{COMMERCIALIZATION POSSIBILITIES}

The commercialization possibilities are very likely as a large number of OEMs and tier 1 suppliers are investigating $\mathrm{SiC}$ and new power module packaging technologies. The proposed solution has a potential to be used as it is a very efficient design, with a low number of $\mathrm{SiC}$ die and manufacturability process is being evaluated and improved. If the final evaluation is positive and good business case is found, the power module can be used in production.

\section{PLANS FOR FUTURE COLLABORATIONS}

Future collaboration potentially is to focus on Weibull analysis to estimate power module lifetime. In addition, it can include the cross-sectional analysis of the build power modules to understand the technical details of the sintering process. 


\section{CONCLUSIONS}

Average shear strength of the silver-sintered test coupons, processed at ORNL using conventional reflow oven processing, was $\sim 50 \mathrm{MPa}$ and remained statistically equivalent through 1000 cycles. Nearly all the specimens had a shear failures stress greater than $40 \mathrm{MPa}$.

The present capability of Weibull statistical analysis software (WeibPar), used by ORNL and others too for nearly 20 years, could not generate user-chosen confidence bounds down to $0.001 \%$. The software vendor (Connecticut Reserve Technologies) was issued a subcontract to enhance the software to be able to generate such confidence bounds down to a $0.001 \%$ probability of failure. The enhanced software was completed and General Motors was supplied a perpetual license of the enhanced WeibPar.

The testing of a Virginia Tech processed device could not be accommodated because its sintered$\mathrm{Ag}$ interconnect exuded out from under the die and wetted up on the die's four sides precluding it from being shear tested. The resulting meniscus inhibited the ability to securely mechanically load against the die causing the tool to scrape over the side.

\section{REFERENCES}

[1] A. A. Wereszczak, M. C. Modugno, B. R. Chen, and W. M. Carty, "Contact Drying of Printed Sinterable-Silver Paste," IEEE Transactions on Components, Packaging and Manufacturing Technology, 7:2079-86 (2017), doi: 10.1109/TCPMT.2017.2752140.

[2] A. A. Wereszczak, B. R. Chen, and B. A. Oistad, "Reflow-Oven-Processing of Pressureless SinteredSilver Interconnects," Journal of Materials Processing Technology, 255:500-506 (2018), doi: 10.1016/j.jmatprotec.2018.01.001.

[3] A. A. Wereszczak, B. R. Chen, B. A. Oistad, S. B. Waters, and A. T. Mayville, "Failure Stress Comparison of Different Pairings of Ag-Plating and Reflow-Oven-Processed PressurelesslySintered-Ag Interconnects," Journal of Materials Science: Materials in Electronics, 29:20189-20198 (2018), doi: 10.1007/s10854-018-0151-5.

[4] Timoshenko, S. P., and Goodier, J. N., 1970, Theory of Elasticity, 3rd Edition, International Student Edition, Mc-Graw-Hill, Singapore.

[5] Wereszczak, A. A., Liang, Z., Ferber, M. K., and Marlino, L. D., 2014, "Uniqueness and Challenges of Sintered Silver as a Bonded Interface Material," Journal of Microelectronics and Electronic Packaging, 11, pp. 158-165.

[6] A. A. Wereszczak, B. R. Chen, O. M. Jadaan, B. A. Oistad, M. C. Modugno, J. W. Sharp, and J. R. Salvador, "Cantilever Testing of Sintered-Silver Interconnects," Journal of Materials Science: Materials in Electronics, 29:1530-1541 (2018), doi: 10.1007/s10854-017-8063-3.

[7] W. Weibull, "A Statistical Distribution Function of Wide Applicability," Journal of Applied Mechanics, 293-297 (1951).

[8] C. A. Johnson, "Fracture Statistics in Design and Application," General Electric CRD Report No 79CRD212, December (1979). 
